\title{
Mechanisms and Time Course of Impaired Skeletal Muscle Glucose Transport Activity in Streptozocin Diabetic Rats
}

Raffaele Napoli, Michael F. Hirshman, and Edward S. Horton

Metabolism Section, Joslin Diabetes Center, Harvard Medical School, Boston, Massachusetts 02215

\begin{abstract}
Skeletal muscle glucose transport is altered in diabetes in humans, as well as in rats. To investigate the mechanisms of this abnormality, we measured glucose transport $V_{\max }$, the total transporter number, their average intrinsic activity, GLUT4 and GLUT1 contents in skeletal muscle plasma membrane vesicles from basal or insulin-stimulated streptozocin diabetic rats with different duration of diabetes, treated or not with phlorizin. The glucose transport $V_{\max }$ progressively decreased with the duration of diabetes. In the basal state, this decrease was primarily associated with the reduction of transporter intrinsic activity, which appeared earlier than any change in transporter number or GLUT4 and GLUT1 content. In the insulin-stimulated state, the decrease of transport was mainly associated with severe defects in transporter translocation. Phlorizin treatment partially increased the insulin-stimulated glucose transport by improving the transporter translocation defects. In conclusion, in streptozocin diabetes $(a)$ reduction of intrinsic activity plays a major and early role in the impairment of basal glucose transport; (b) a defect in transporter translocation is the mechanism responsible for the decrease in insulin-stimulated glucose transport; and (c) hyperglycemia per se affects the insulin-stimulated glucose transport by altering the transporter translocation. (J. Clin. Invest. 1995. 96:427-437.) Key words: GLUT4 • GLUT1 • hyperglycemia - intrinsic activity $\bullet$ insulin resistance
\end{abstract}

\section{Introduction}

Both type I and type II diabetes mellitus are characterized by impairment of insulin-mediated skeletal muscle glucose uptake (1-5). Since under physiological circumstances the rate of glucose transport across the plasma membrane is the rate-limiting step for glucose utilization by the skeletal muscle tissue (611 ), abnormalities of this step are important in determining impairment of skeletal muscle glucose uptake. Recently, it has been shown that skeletal muscle glucose transport is impaired

Portions of this research were presented in abstract form at the 1994 Annual Meeting of the American Diabetes Association in New Orleans on June 11-14 1994.

Address correspondence to Raffaele Napoli, M.D., Metabolism Section, Joslin Diabetes Center, One Joslin Place, Boston, MA 02215. Phone: 617-732-2699x4377; FAX: 617-732-2650.

Received for publication 10 January 1995 and accepted in revised form 11 March 1995.

J. Clin. Invest.

(C) The American Society for Clinical Investigation, Inc.

0021-9738/95/07/0427/11 \$2.00

Volume 96, July 1995, 427-437 in diabetic patients in vivo (11). However, the exact mechanisms by which glucose transport is impaired are still unknown.

Glucose transport in the skeletal muscle is mediated by specific carrier proteins: viz. GLUT4, which is quantitatively the most relevant transporter in this tissue (12-14) and translocates from an intracellular pool to the plasma membrane (PM) ${ }^{1}$ in response to insulin stimulation (15-18), and GLUT1, which is generally considered to be insulin independent (16-18). Nevertheless, in humans with diabetes, no changes in the GLUT4 content of the whole muscle have been detected (1923). However, whole muscle GLUT4 content includes both the functionally active transporters located on the plasma membrane and the transporters located in the intracellular microsomal pool, which do not transport glucose into the cell. The few data available on the GLUT4 content in skeletal muscle plasma membranes of diabetic patients are conflicting, showing either a decrease (24) or no change (25). However, skeletal muscle glucose transport can be regulated not only by changes in the number of glucose transporters located on the plasma membrane, but also by changes in their functional activity (26-33). Therefore, it is possible that reductions of the glucose transport occur because of the impairment of glucose transporter intrinsic activity, rather than transporter number. Currently, no data are available on glucose transporter intrinsic activity in human diabetes.

In contrast to human diabetes, streptozocin (STZ)-induced diabetes in rodents is characterized by a reduction of total glucose transporter number and GLUT4 content in the whole muscle (34-37) as well as in the plasma membrane, both in the basal state $(16,35,37)$ and after insulin stimulation (16). Nevertheless, the reductions of insulin-stimulated skeletal muscle glucose uptake $(36,38,39)$ and transport $(16,34)$ are not proportionally related to the changes in glucose transporter number, when measured either in the whole muscle $(34,36)$ or in the plasma membrane fraction (16). Consequently, the available data indicate that in STZ diabetes changes in transporter intrinsic activity may also be relevant. In addition, in the initial stages of STZ diabetes it is possible to detect a reduction of insulin-stimulated whole body $(38,39)$ and skeletal muscle glucose uptake (36) and transport (34) although there is no change in the whole muscle and in the plasma membrane GLUT4 or GLUT1 content, as we will show. Under the latter circumstances, the role of intrinsic activity can be more easily studied and clarified without the confounding changes in transporter number and/or different isoform content. Thus, clarifying the role that changes in transporter intrinsic activity may play in the impairment of glucose transport in STZ diabetes would have potentially important implications for human diabetes.

1. Abbreviations used in this paper: $\mathrm{CB}$, Cytochalasin $\mathrm{B} ; \mathrm{HM}$, homogenate; $P M$, plasma membrane; $R_{0}$, plasma membrane glucose transporters measured by Cytochalasin B binding; STZ, streptozocin. 
Therefore, we studied the extent to which glucose transporter intrinsic activity is affected in STZ induced diabetic rats and its contribution to the impairment of skeletal muscle glucose transport. In addition, we evaluated whether the appearance of a defect in the average transporter intrinsic activity in the development of STZ diabetes is associated with, or independent of, changes in plasma membrane transporter number and/or isoform content.

Since hyperglycemia affects insulin-mediated whole body glucose uptake in partially pancreatectomized or STZ diabetic rats $(40,41)$, a further aim of the current study was to clarify the role that hyperglycemia plays in the abnormalities observed in the skeletal muscle glucose transport system after insulin stimulation. For this purpose, we treated diabetic rats with phlorizin, a drug that reduces hyperglycemia without a direct effect on insulin sensitivity.

\section{Methods}

Animals and experimental design. 79 Male Sprague-Dawley rats weighing 125-150 grams were obtained from Charles River Laboratories Canada (Montreal, Quebec, Canada); all animals were housed at $23^{\circ} \mathrm{C}$ with a 12-h light/dark cycle and fed ad libitum for several days before the start of the study. The rats were then randomly divided into six different groups: in one group, 21 control rats, receiving an i.p. injection of saline, were studied either 1,5 , or $10 \mathrm{~d}$ after injection; in a second group (1-d diabetic), 9 rats were treated with a single i.p. injection of STZ ( $125 \mathrm{mg} / \mathrm{kg}$ of body weight $)$ and studied $24 \mathrm{~h}$ later, in a third group (5-d diabetic), 16 animals were made diabetic by a single i.p. injection of STZ $(85 \mathrm{mg} / \mathrm{kg})$ and were studied $5 \mathrm{~d}$ later; 23 diabetic rats, made diabetic by a single i.p. injection of STZ $(85 \mathrm{mg} /$ $\mathrm{kg}$ ), were studied $10 \mathrm{~d}$ later, either untreated (10-d diabetic, $n=11$ ), or phlorizin treated (phlorizin-treated diabetic, $n=12$ ); finally, 10 control rats (phlorizin control), receiving an i.p. injection of saline, were treated with phlorizin. Phlorizin was administered for $8 \mathrm{~d}$ s.c. $(0.4$ grams $/ \mathrm{kg}$ body weight per day, prepared as a $40 \%$ solution in propylene glycol) starting on day 2 after the saline (controls) or the STZ injection ( $10 \mathrm{~d}$ diabetic animals). The phlorizin was administered via a small implantable osmotic minipump both in the control and in the diabetic animals (Alzet Osmotic Minipump, Alza Corp., Palo Alto, CA). STZ was always freshly dissolved in $50 \mathrm{mM}$ citric acid before injection and administered to rats in the nonfasted condition. The rats treated with STZ were allowed to drink $10 \%(\mathrm{wt} / \mathrm{vol})$ sucrose in tap water ad libitum for the first $24 \mathrm{~h}$ to avoid fatal hypoglycemia $(42,43)$. In 1-d diabetic rats, tail plasma glucose level was evaluated several times after the STZ injection and constant hyperglycemia was not observed before $12 \mathrm{~h}$. In all the other diabetic rats, plasma glucose concentration was measured $2 \mathrm{~d}$ after STZ administration and every 2 or $3 \mathrm{~d}$ in the following period. Rats were considered diabetic when second day nonfasted plasma glucose level was $>300 \mathrm{mg} / \mathrm{dl}$. All animals were studied between 8:30 and 10:30 a.m. in the nonfasted state either under basal physiological conditions or after maximal insulin stimulation. Maximal insulin stimulation was achieved by intraperitoneal injection of $20 \mathrm{U}$ of insulin 30 min before killing the animals. The rats were considered insulin stimulated when plasma insulin concentration exceeded $20,000 \mu \mathrm{U} / \mathrm{ml}$. To assess the fall in plasma glucose concentration in the $30 \mathrm{~min}$ after the i.p. injection of $20 \mathrm{IU}$ of insulin, an independent group of 17 control rats were studied before or 5, 10, 20, and $30 \mathrm{~min}$ after the insulin injection: the plasma glucose progressively and gradually fell from the basal value to the value measured at $30 \mathrm{~min}$, without hypoglycemic episodes in between (data not shown). Basal animals were handled but received no i.p. injection.

Procedures. At 7 a.m., in rats receiving insulin injection (with the exception of one rat from the $10 \mathrm{~d}$ diabetic group), tail plasma glucose concentration was measured. The animals were killed by a blow to the head followed by decapitation, and the blood was collected for glucose and insulin measurements. The gastrocnemius muscle from both legs was then quickly exposed, and 6 grams of muscle (soleus, red and white gastrocnemius) was rapidly dissected, removing fat and connective tissue.

Plasma membrane preparation. To measure glucose transport and the functional activities of transporters in the muscle, it is necessary to prepare a solution particularly enriched in plasma membranes. The method for preparing PMs was derived from the methods of Bers (44) and Grimditch et al. (45) as modified by Hirshman et al. (15). The dissected muscle was weighed and homogenized by mincing, polytroning, and homogenizing in a Potter-Elvejhem homogenizer using a sucrose/Hepes buffer ( $250 \mathrm{mM}$ sucrose, $20 \mathrm{mM} \mathrm{N}$-2-hydroxyethylpiperazine- $N^{\prime}$-2-ethanesulfonic acid (Hepes), $\mathrm{pH} 7.4$ at $4^{\circ} \mathrm{C}$ ). After measuring the total volume, a small aliquot of this homogenate (HM) was taken and later used for 5 '-nucleotidase, a plasma membrane marker enzyme, for protein determinations, and for Western blotting. The following steps were performed at $4^{\circ} \mathrm{C}$. To solubilize, and then later remove, the muscle contractile proteins, $\mathrm{KCl}$ and sodium pyrophosphate (final concentration 300 and $25 \mathrm{mM}$, respectively) were added to the $\mathrm{HM}$ and mixed. The mixture was then centrifuged for $1 \mathrm{~h}$ at $227,000 \mathrm{~g}$. The supernatant was discarded, and the pellet was resuspended with sucrose/Hepes buffer. DNase was added (2000 U/ml final volume) and the suspension incubated for $60 \mathrm{~min}$ in a $30^{\circ} \mathrm{C}$ shaking waterbath, then diluted with sucrose/ Hepes buffer and centrifuged for $1 \mathrm{~h}$ at $227,000 \mathrm{~g}$. The resulting pellet was then resuspended in $34 \%$ sucrose $/ 20 \mathrm{mM}$ Hepes buffer, layered in a discontinuous sucrose gradient $(45,34,32,30,27$, and $12 \%)$, and centrifuged for $16.5 \mathrm{~h}$ in a swinging bucket SW 28 rotor (Beckman Instruments Inc., Fullerton, CA) at $68,000 \mathrm{~g}$. Fractions were collected from the gradient at the $12 / 27$ and $27 / 30$ interfaces. This fraction was chosen since it was particularly enriched in 5 '-nucleotidase and other plasma membrane markers, indicating an enrichment in plasma membrane. The fraction was diluted with double distilled water and centrifuged at $227,000 \mathrm{~g}$ for $1 \mathrm{~h}$. The resulting pellets were resuspended in sucrose/Hepes buffer to a final protein concentration of $1.5-3.0 \mathrm{mg} /$ $\mathrm{ml}$. An aliquot from each suspension was then removed and used for 5 '-nucleotidase and protein determinations, whereas the remaining sample was stored in liquid nitrogen until used for measurement of glucose transport activity, total glucose transporter number by Cytochalasin B (CB) binding, and GLUT4 and GLUT1 content by Western blotting.

Enzyme and protein determinations. In order to obtain data on the recovery and enrichment in plasma membrane of the final PM fraction, 5 '-nucleotidase activity (46), a marker enzyme for sarcolemma, was measured in the original HM and in the final PM preparation. Protein concentration was measured by the Coomassie brilliant blue method (Bio-Rad protein assay, Bio-Rad Laboratories, Inc., Richmond, CA) as described by Bradford (47). 5'-Nucleotidase enrichment was calculated by dividing the 5 '-nucleotidase activity per milligram of protein in the PM by that in the HM.

Transport measurement. The fragments of plasma membrane in the final plasma membrane preparation sample spontaneously seal to form vesicles in which it is possible to measure the glucose uptake. Under these circumstances, when no more cytoplasmic enzymatic activities are present, the glucose uptake into the vesicles is regulated exclusively by the glucose transport. D- $\left({ }^{14} \mathrm{C}\right)$ glucose and $\mathrm{L}-\left({ }^{3} \mathrm{H}\right)$ glucose uptake into membrane vesicles were measured under conditions of equilibrium exchange ([glucose ]in $=$ [glucose ] out) using a rapid filtration technique as described by King et al. (27). The sarcolemma vesicles were diluted with a large volume of Krebs-Ringer solution containing glucose ( $135 \mathrm{mM} \mathrm{NaCl}, 5 \mathrm{mM} \mathrm{KCl}, 1.2 \mathrm{mM} \mathrm{MgCl}, 20 \mathrm{mM}$ Hepes, pH 7.6 at $25^{\circ} \mathrm{C}$, and equal concentration of L- and D-glucose), briefly homogenized (Potter-Elvehjem tissue grinder [Thomas Scientific, Swèdesboro, $\mathrm{NJ}]$ at $4^{\circ} \mathrm{C}$ ) and centrifuged at $34,000 \mathrm{~g}$ for $1 \mathrm{~h}$ at $4^{\circ} \mathrm{C}$. The supernatant was discarded and the pellet resuspended in a small volume of the Krebs-Ringer solution with glucose. A small aliquot was taken from this final membrane suspension for protein determination. The remaining membranes were kept on ice until the start of the transport experiments $(\sim 90 \mathrm{~min})$. The incubation media were the same solutions as used to dilute and resuspended the vesicles, except for the presence of $6 \mu \mathrm{Ci}$ 
Table I. General Characteristics of Control and Diabetic Rats

\begin{tabular}{|c|c|c|c|c|c|c|}
\hline \multirow[b]{2}{*}{ Groups } & \multirow[b]{2}{*}{ Untreated controls } & \multicolumn{3}{|c|}{ Diabetics } & \multicolumn{2}{|c|}{ Phlorizin-treated } \\
\hline & & $1-\mathrm{d}$ & 5-d & 10-d & Diabetics & Controls \\
\hline \multicolumn{7}{|l|}{ Basal rats } \\
\hline Body weight (grams) & $208 \pm 10$ & $167 \pm 6^{*}$ & $173 \pm 4 *$ & $214 \pm 11$ & $214 \pm 6$ & $244 \pm 9^{\ddagger}$ \\
\hline Plasma glucose $(\mathrm{mg} / \mathrm{dl})$ & $155 \pm 3$ & $470 \pm 15^{\ddagger}$ & $525 \pm 16^{\ddagger}$ & $553 \pm 32^{\ddagger}$ & $303 \pm 14^{\ddagger \S}$ & $152 \pm 6$ \\
\hline Insulin RIA $(\mu \mathrm{U} / \mathrm{ml})$ & $50 \pm 6$ & $15 \pm 1^{*}$ & $13 \pm 2 *$ & $23 \pm 3 *$ & $27 \pm 4 *$ & $34 \pm 4$ \\
\hline Plasma glucose during treatment $(\mathrm{mg} / \mathrm{dl})$ & & & & & $286 \pm 22$ & \\
\hline \multicolumn{7}{|l|}{ Insulin-stimulated rats } \\
\hline Body weight (grams) & $202 \pm 8$ & $177 \pm 2 *$ & $174 \pm 3 *$ & $201 \pm 8$ & $199 \pm 8$ & $243 \pm 8^{*}$ \\
\hline Plasma glucose $(\mathrm{mg} / \mathrm{dl})$ & $76 \pm 3$ & $61 \pm 4$ & $221 \pm 11 *$ & $384 \pm 20 *$ & $114 \pm 13^{* \S}$ & $55 \pm 4$ \\
\hline Plasma glucose during treatment $(\mathrm{mg} / \mathrm{dl})$ & & & & & $299 \pm 30$ & \\
\hline
\end{tabular}

Values are means \pm SE. The value indicated as plasma glucose during the treatment in the phlorizin-treated (10-d) diabetic rats represents the average of three to five measurements obtained from each rat in that group in the basal nonfasted state on different days during the phlorizin treatment. ${ }^{*} P<0.01,{ }^{\ddagger} P<0.005$ vs. controls; ${ }^{8} P<0.001$ vs. 10 -d diabetic group.

of $\mathrm{L}-\left({ }^{3} \mathrm{H}\right)$ glucose $(20 \mathrm{Ci} / \mathrm{mmol})$ and $1.6 \mu \mathrm{Ci}$ of $\mathrm{D}-\left({ }^{14} \mathrm{C}\right)$ glucose $(265$ $\mathrm{mCi} / \mathrm{mmol}$ ), both from NEN-DuPont (Boston, MA). The uptake was initiated by combining vesicles and incubation medium and stopped by the addition of $1 \mathrm{ml}$ of ice-cold stop solution $(20 \mathrm{mM} \mathrm{NaCl}, 5 \mathrm{mM}$ $\mathrm{KCl}, 1.2 \mathrm{mM} \mathrm{MgCl} 2,20 \mathrm{mM}$ Hepes, $\mathrm{pH} 7.8$ at $4^{\circ} \mathrm{C}$ ) containing 0.2 $\mathrm{mM}$ phloretin. The vesicles were then quickly transferred to a nitrocellulose filter (Millipore Corp., Bedford, MA) under vacuum. The filter was washed with an additional $6 \mathrm{ml}$ of stop solution and analyzed by liquid scintillation counting, using quench correction for a dual label. To determine the initial rate, the uptake was stopped after $0,1,3$, and $5 \mathrm{~s}$ with vesicles from basal rats, and at time $0,1,1.5$, and $2 \mathrm{~s}$ in those from maximally insulin-stimulated animals. Equilibrium time measurement was made at 120 min for both experimental conditions. Carriermediated transport was quantitated by subtracting the initial rate of Lglucose influx from that of D-glucose, obtained from a graph of influx (in nanomoles per milligram of protein) versus time of L- and D-glucose. The rates of carrier-mediated influx were then graphed versus glucose concentration (1-60 mM) and $V_{\max }$ and $K_{\mathrm{m}}$ obtained by a nonlinear least-squares fit (48) of the data.

Cytochalasin $B$ binding. The total amount of glucose transporters in PMs was measured by equilibrium D-glucose inhibitable ${ }^{3} \mathrm{H}-\mathrm{CB}$ binding as described by Wardzala et al. (49). Scatchard plots were generated from four-point binding studies in which membranes were incubated with varying $\mathrm{CB}$ concentrations in the absence or in the presence of $500 \mathrm{mM}$ D-glucose. To decrease nonspecific binding, cytochalasin $\mathrm{E}$ was used. The total number of transporters $\left(R_{0}\right)$ and the dissociation constant $\left(K_{\mathrm{d}}\right)$ were determined from a linear plot derived by subtracting along the radial axes the binding curves generated in the presence of D-glucose from those in its absence.

Carrier turnover number. The carrier turnover number, an index of glucose transported per transporter $(14,27)$, was calculated by dividing the glucose transport $V_{\max }$ by the total number of glucose transporters, measured in the same plasma membrane vesicles $\left(V_{\max } / \mathrm{R}_{\mathrm{o}}\right)$. The carrier turnover number represents the average intrinsic activity of transporters in the PM. Therefore, variations in PM isoform population, if they had different intrinsic activities, would result in change of the calculated average carrier turnover number even if no real change of transporter intrinsic activity occurs.

Western blot. HM (100 $\mu \mathrm{g})$ and PM (20 $\mu \mathrm{g}$ for GLUT4, $50 \mu \mathrm{g}$ for GLUT1 ) protein and molecular weight markers (Bio-Rad Laboratories) were subjected to SDS-PAGE and resolved proteins were transferred to nitrocellulose filters $(50,51)$. Incubations were carried out in Trisbuffered saline ( $20 \mathrm{mM}$ Tris, $250 \mathrm{mM} \mathrm{NaCl}, \mathrm{pH} 7.5$ at $22^{\circ} \mathrm{C}$ ), unless otherwise indicated. The nitrocellulose transfer membranes were blocked in Tris-buffered saline with $0.5 \%$ Tween 20 , 3\% BSA, $0.01 \%$ $\mathrm{Na}$ azide. For GLUT1 determination, Carnation nonfat dry milk was added to the previous blocking buffer ( $2 \%$ final concentration). To identify GLUT4 or GLUT1 proteins, the transfer membranes were incubated with either a polyclonal antibody $\alpha$ GT4 at a dilution of 1:250 (produced from a synthetic peptide corresponding to a 15-amino acid COOH-terminal sequence in rat muscle GLUT4, gift of Dr. Robert J. Smith, Boston, MA) or the polyclonal antibody (East-Acres Biologicals, Southbridge, MA) (52) produced from a synthetic peptide corresponding to a 12-amino acid COOH-terminal sequence in rat brain GLUT1) at the dilution 1:200, followed by incubation with ${ }^{125}$ I-labeled protein A (ICN Biomedicals, Inc., Irvine, CA). The nitrocellulose filters were analyzed on a PhosphorImager (Molecular Dynamics, Sunnyvale, CA). Bands corresponding to specific glucose transporters were quantitated. For each gel, serial dilutions of a microsomal membrane stock were run as internal standard to allow a comparison of samples run in separate gels and to determine linearity.

Statistical analysis. All data were compared using SAS (Statistical Analysis System, Cary, NC) programs. Group means were compared by two-way analysis of variance using the general linear models procedure with least squares means for the among-groups comparisons. The differences between groups were accepted to be significant when $P$ $<0.05$. Data are expressed as means $\pm \mathrm{SE}$.

\section{Results}

\section{General characteristics of the rats studied}

The general characteristics of the rats studied are shown in Table I. In the basal state, plasma glucose concentration significantly increased in all diabetic animals following the STZ injection, compared with the controls $(P<0.005)$. Phlorizin treatment significantly reduced plasma glucose in diabetic animals $(P$ $<0.001$ ), but did not change glucose levels in the control rats. In all the diabetic animals, the basal insulin concentration was significantly reduced compared with controls $(P<0.01$ for all $)$ with no effect of phlorizin treatment. In the phlorizin-treated controls, the basal insulin level was slightly, but not significantly lower than in the untreated controls.

\section{Enzymatic characterization of PMs}

To characterize our PM preparations and to evaluate whether relevant differences in PM content were present in the samples prepared from rats of different groups, we measured 5 '-nucleotidase activity in the HM and PM fractions of all rats (Table II). Compared with the controls, there were no differences in 
Table II. 5'-Nucleotidase Activity in Skeletal Muscle Plasma Membranes from Control and Diabetic Rats

\begin{tabular}{|c|c|c|c|}
\hline & HM activity & PM activity & Enrichment \\
\hline & $n \operatorname{mol}(\mathbf{m g} \cdot \min )$ & $n \operatorname{mol} /(m g \cdot \min )$ & fold \\
\hline \multicolumn{4}{|l|}{ Controls } \\
\hline Basal & $3.58 \pm 0.21$ & $96.67 \pm 5.17$ & $27.3 \pm 1.3$ \\
\hline Insulin & $3.48 \pm 0.24$ & $101.82 \pm 4.57$ & $29.9 \pm 1.6$ \\
\hline \multicolumn{4}{|c|}{ 1-d diabetics } \\
\hline Basal & $3.49 \pm 0.34$ & $101.52 \pm 2.28$ & $29.6 \pm 2.1$ \\
\hline Insulin & $3.83 \pm 0.34$ & $100.51 \pm 4.32$ & $26.8 \pm 1.9$ \\
\hline \multicolumn{4}{|c|}{ 5-d diabetics } \\
\hline Basal & $3.43 \pm 0.18$ & $99.79 \pm 6.36$ & $29.3 \pm 1.8$ \\
\hline Insulin & $3.59 \pm 0.29$ & $99.24 \pm 5.83$ & $28.8 \pm 2.4$ \\
\hline \multicolumn{4}{|c|}{ 10-d diabetics } \\
\hline Basal & - $4.22 \pm 0.37$ & $129.98 \pm 7.98^{\ddagger}$ & $31.4 \pm 2.2$ \\
\hline Insulin & $4.13 \pm 0.30$ & $121.86 \pm 8.14 *$ & $30.4 \pm 3.6$ \\
\hline \multicolumn{4}{|c|}{$\begin{array}{l}\text { Phlorizin-treated } 10-\mathrm{d} \\
\text { diabetics }\end{array}$} \\
\hline Basal & $4.27 \pm 0.33$ & $107.35 \pm 7.95$ & $25.3 \pm 1.6$ \\
\hline Insulin & $3.77 \pm 0.18$ & $113.15 \pm 9.38$ & $30.8 \pm 3.9$ \\
\hline \multicolumn{4}{|c|}{ Phlorizin-treated controls } \\
\hline Basal & $3.67 \pm 0.14$ & $83.48 \pm 7.86$ & $23.0 \pm 2.8$ \\
\hline Insulin & $4.21 \pm 0.24$ & $80.65 \pm 2.72 *$ & $19.3 \pm 1.0 *$ \\
\hline
\end{tabular}

Values are means $\pm S E$. The enrichment was calculated as the ratio between PM and HM 5'-nucleotidase activities. ${ }^{*} P<0.05,{ }^{\ddagger} P$ $<0.001$ vs. corresponding condition of untreated controls.

HM enzyme activities in any of the groups studied. PM 5'nucleotidase activity was slightly, although significantly, higher in the 10-d diabetic animals compared with the controls. Nevertheless, the fold enrichment in plasma membrane marker from the starting HM was similar to the controls for all the diabetic animals. Compared with the untreated controls, a slight reduction in 5'-nucleotidase activity and enrichment was detected in the insulin-stimulated phlorizin-treated controls. Finally, no differences were present in any group between basal and insulinstimulated rats for 5'-nucleotidase activities or enrichment. The recovery of $5^{\prime}$-nucleotidase activity, calculated as the ratio between the total activity in the PM fraction and total activity in the HM fraction is an expression of yield of plasma membrane recovery from the original muscles and was $>10 \%$ for all the groups studied (data not shown).

\section{Untreated control and diabetic animals}

Glucose transport measurements. The glucose transport $V_{\max }$ data related to the untreated control and diabetic rats are shown in Table III. In the basal state, glucose transport $V_{\max }$ was unchanged after $1 \mathrm{~d}$ of diabetes, decreased, although not significantly, after $5 \mathrm{~d}$ of diabetes $(-45 \%, P=0.06$ vs. controls), and was markedly impaired after $10 \mathrm{~d}(-84 \%, P<0.005$, vs. controls). The time course of impairment of glucose transport $V_{\max }$ with diabetes was different in the insulin-stimulated state compared with the basal state. Surprisingly, the insulin-stimulated $V_{\max }$ was increased compared with controls after $1 \mathrm{~d}$ of diabetes $(P<0.05$ vs. controls $)$. After $5 \mathrm{~d}$ of diabetes, the insulin-stimulated $V_{\max }$ was similar to that of the controls. Therefore, in this group, although the glucose transport was substantially impaired in the basal state, it was completely normal after insulin stimulation. In the 10-d diabetic animals, the insulinstimulated glucose transport $V_{\max }$ was markedly reduced by $58 \%$ ( $P<0.001$ vs. controls), reaching a value similar to that of the control rats in the basal state. In all the groups studied, including the 10-d diabetic animals, maximal insulin stimulation significantly increased the glucose transport $V_{\max }$ compared with corresponding basal values $(0.02>P>0.001)$.

In the basal state, in all the groups, the $K_{\mathrm{m}}$ for the glucose transport was not different from that of the controls $(26.7 \pm 2.3$, $25.1 \pm 1.7,23.0 \pm 4.1$, and $17.7 \pm 3.1 \mathrm{mM}$, in control, 1-, 5-, and 10-d diabetic groups, respectively). Insulin stimulation did not change the $K_{\mathrm{m}}$ in any group, and no differences were found between diabetic and control rats $(35.1 \pm 3.3,35.1 \pm 4.6$, $32.5 \pm 2.7$, and $26.8 \pm 5.8 \mathrm{mM}$, in control, 1-, 5-, and 10-d diabetic groups, respectively).

Total glucose transporter number. Cytochalasin B binds all the glucose transporters without distinction among different isoforms. This property is used to measure the total number of glucose transporters in the plasma membrane. The number of transporter sites in the PM vesicles, $R_{0}$, measured by glucose inhibitable CB binding, are shown in Table III. In the basal state, compared with the control group, the $\mathbf{R}_{\mathbf{o}}$ did not change after 1 or $5 \mathrm{~d}$ of diabetes $(P=\mathrm{NS})$, even though the $V_{\max }$ was substantially decreased after $5 \mathrm{~d}$. Only at day 10 was the $R_{o}$ markedly reduced ( $-45 \%, P<0.001$, vs. control group).

After maximal insulin stimulation, the total number of glucose transporters on the plasma membrane significantly increased in all the groups $(P<0.001$ vs. their own basal values for all), except in the 10-d diabetic animals where they remained statistically unchanged, demonstrating a marked defect in the insulin-induced transporter translocation ( $P=\mathrm{NS}$ vs. basal, and $P<0.001$ vs. controls).

Therefore, no reduction of the glucose transporters in the plasma membrane could be detected earlier than $10 \mathrm{~d}$ after the STZ injection in both the basal and insulin-stimulated states, as measured by $\mathrm{CB}$ binding.

The dissociation coefficient for the CB binding, $K_{\mathrm{d}}$, an index of affinity for the glucose transporters, did not show any difference among the groups studied or between basal (109 \pm 9.1 , $134 \pm 11,116 \pm 8.1$, and $124 \pm 11 \mathrm{nM}$, in control, 1-, 5-, and 10-d diabetic animals, respectively) and insulin-stimulated (139 \pm 12 , $128 \pm 13,130 \pm 12$, and $96 \pm 10 \mathrm{nM}$, in control, 1-, 5-, and 10-d diabetic animals, respectively) states.

GLUT4 and GLUT1 content. The contents of GLUT4 protein in the whole muscle $\mathrm{HM}$, in arbitrary units of a reference standard, are shown in Fig. 1. Because there were no differences between the basal and the insulin-stimulated states for all the groups studied, these data have been combined. Whole muscle HM GLUT4 protein content was similar in control, 1- and 5-d diabetic rats $(11.7 \pm 1.0,11.7 \pm 1.7$, and $8.6 \pm 1.0$ arbitrary units, respectively). In the 10-d diabetic group, the HM GLUT4 was significantly reduced $(6.0 \pm 0.8$ arbitrary units, $P<0.01$ vs. controls).

PM GLUT4 and GLUT1 protein contents were measured in the same PM vesicle preparations used for the CB binding measurements. The data for GLUT4, shown in Fig. 2, closely parallel those of the total number of glucose transporters $\left(R_{o}\right)$ in PM. In the basal state, PM GLUT4 protein content was not changed by either $24 \mathrm{~h}$ or $5 \mathrm{~d}$ of STZ diabetes, but was decreased by $50 \%$ after $10 \mathrm{~d}(10.2 \pm 0.9$ and $5.0 \pm 0.4$ arbitrary units, in controls and 10-d diabetics, respectively, $P<0.001$ ). In controls, insulin stimulation increased PM GLUT4 50\% above the 


\begin{tabular}{|c|c|c|c|c|c|c|}
\hline \multirow[b]{2}{*}{ Groups } & \multirow[b]{2}{*}{ Untreated controls } & \multicolumn{3}{|c|}{ Diabetics } & \multicolumn{2}{|c|}{ Phlorizin-treated } \\
\hline & & $1-\mathrm{d}$ & 5-d & $10-d$ & $10-\mathrm{d}$ & Controls \\
\hline \multicolumn{7}{|l|}{$V_{\max }[\mathrm{nmol} /(\mathrm{mg} \cdot \mathrm{s})]$} \\
\hline Basal & $7.5 \pm 0.8$ & $6.9 \pm 1.5$ & $4.1 \pm 0.3$ & $1.2 \pm 0.2^{\S}$ & $1.7 \pm 0.2^{8}$ & $5.9 \pm 0.7$ \\
\hline Insulin & $17.4 \pm 2.1$ & $22.7 \pm 2.1 *$ & $16.4 \pm 1.5$ & $7.3 \pm 0.8^{8}$ & $10.1 \pm 1.0^{\S}$ & $16.9 \pm 2.5$ \\
\hline \multicolumn{7}{|l|}{$\mathrm{R}_{\mathrm{o}}(\mathrm{pmol} / \mathrm{mg})$} \\
\hline Basal & $7.6 \pm 0.5$ & $7.2 \pm 0.3$ & $6.8 \pm 0.2$ & $4.3 \pm 0.3^{8}$ & $5.5 \pm 0.5^{\ddagger}$ & $7.1 \pm 0.8$ \\
\hline Insulin & $11.5 \pm 0.4$ & $11.7 \pm 0.9$ & $10.0 \pm 0.6$ & $6.1 \pm 0.8^{8}$ & $9.0 \pm 1.1^{\neq \|}$ & $10.6 \pm 1.7$ \\
\hline \multicolumn{7}{|c|}{ Carrier turnover number $(1 / \mathrm{s})$} \\
\hline Basal & $1002 \pm 101$ & $967 \pm 221$ & $609 \pm 52 *$ & $280 \pm 39^{8}$ & $299 \pm 30^{8}$ & $871 \pm 115$ \\
\hline Insulin & $1516 \pm 181$ & $1945 \pm 114 *$ & $1708 \pm 206$ & $1320 \pm 271$ & $1216 \pm 199$ & $1636 \pm 137$ \\
\hline
\end{tabular}

Values are means \pm SE. ${ }^{*} P<0.05,{ }^{\ddagger} P<0.02,{ }^{8} P<0.005$ vs. corresponding value of untreated controls. " $P=0.01$ vs. 10 -d untreated diabetics.

basal value $(P<0.001)$. Insulin induced a significant increase of PM GLUT4 in the 1- and 5-d diabetic rats $(P<0.001$ and $P<0.005$ vs. the corresponding basal values, respectively). In particular, the 1-d diabetic group reached a level higher than that of controls $(P<0.05)$. After $10 \mathrm{~d}$ of diabetes, a marked defect in GLUT4 translocation was observed, because insulin did not induce an increase of PM GLUT4 (5.0 \pm 0.4 and 7.1 \pm 0.4 arbitrary units, in the basal state and after insulin stimulation, respectively, $P=0.17$ vs. the basal value, $P<0.001$ vs. controls).

PM GLUT1 data are shown in Fig. 3. In the basal state, no differences were observed among the groups studied, although a clear trend toward an increase with the duration of diabetes was observed $(8.7 \pm 0.7$ and $11.2 \pm 0.9$ arbitrary units, in controls and 10-d diabetics, respectively, $P=0.07$ ). Surprisingly, insulin stimulation induced a significant increase in PM GLUT1 in the controls (from $8.7 \pm 0.7$ to $12.4 \pm 0.9$ arbitrary units, $P$

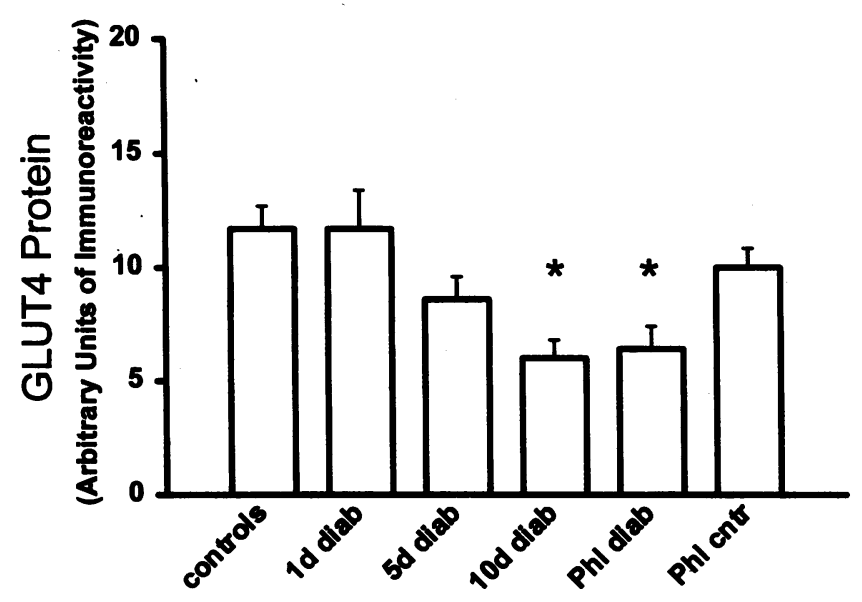

Figure 1. PhosphorImager analysis of Western blots of whole muscle homogenate GLUT4 protein from control and diabetic rats. Because there were no differences between the basal and the insulin-stimulated state for all the groups studied, these data have been combined for each group. Thus, each column represents the data from all the animals studied in that group. The data are expressed as arbitrary units of a reference standard used for the comparisons among different blots. Results are means \pm SE. $* P<0.05$ vs. the untreated control group.
$<0.002)$. PM GLUT1 increased after insulin stimulation slightly in $1-\mathrm{d}$ diabetics (from $7.4 \pm 1.0$ to $10.0 \pm 0.3$ arbitrary units, $P=0.13$ ) and significantly in 5-d diabetics (from 9.3 \pm 1.2 to $11.8 \pm 1.1$ arbitrary units, $P<0.05$ ), but not in 10 -d diabetics. Compared with the controls, no differences in PM GLUT1 were observed in the insulin-stimulated diabetic rats.

Carrier turnover number. Since we measured both the glucose transport $V_{\max }$ and the total number of glucose transporters in the same plasma membrane preparations, we could calculate an average intrinsic activity for the transporters present on the plasma membrane $\left(V_{\max } / \mathrm{R}_{\mathrm{o}}=\right.$ carrier turnover number, Table III). In the basal state, compared with the controls, the carrier turnover number was unchanged after $24 \mathrm{~h}$ of diabetes. After $5 \mathrm{~d}$ of diabetes, the glucose transport $V_{\max }$ decreased by $45 \%$, and was not associated with change in $R_{0}$, resulting in a $39 \%$ reduction of the carrier turnover number $(P<0.05$ vs. controls). In the 10-d diabetic rats, the severe decrease of glucose transport $V_{\max }$ was due to the combined effect of a reduction of $\mathrm{R}_{\mathrm{o}}$ and a marked impairment of carrier turnover number $(P$

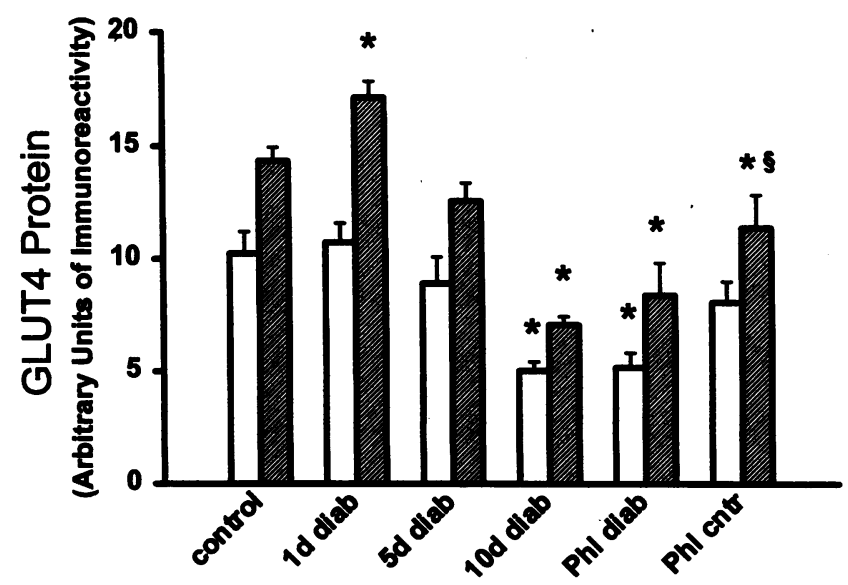

Figure 2. PhosphorImager analysis of Western blots of skeletal muscle plasma membrane GLUT4 protein from control and diabetic animals in basal state $(\square)$ and after maximal insulin stimulation ( $\square)$. The data are expressed as arbitrary units of a reference standard used for the comparisons among different blots. Results are means \pm SE. ${ }^{*} P<0.05$ vs. the untreated control group. ${ }^{\S} P<0.05$ vs. the 10 -d diabetic group. 


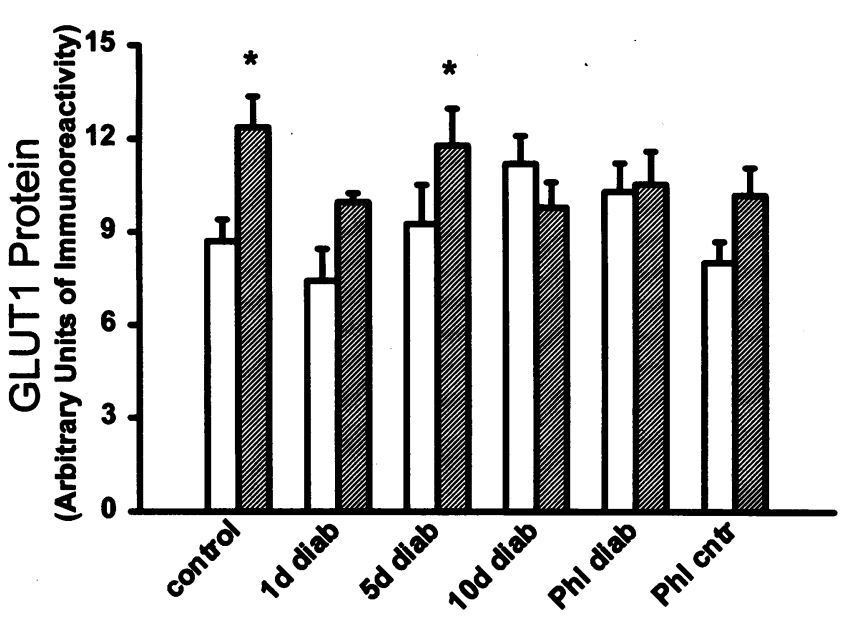

Figure 3. PhosphorImager analysis of Western blots of skeletal muscle plasma membrane GLUT1 protein from control and diabetic animals in basal state ( $\square$ ) and after maximal insulin stimulation ( $\square$ ). The data are expressed as arbitrary units of a reference standard used for the comparisons among different blots. Results are means \pm SE. $* P<0.05$ vs. corresponding basal value.

$<0.001$ vs. controls). Therefore, in the basal state, transporter intrinsic activity is severely impaired with diabetes and this impairment occurs earlier than any change in plasma membrane total glucose transporter number, GLUT4, and GLUT1 content. Insulin stimulation significantly increased the carrier turnover number in all the groups $(P<0.005$ vs. the basal values, for all groups). Compared with the controls, 1-d diabetics showed an increase of the insulin-stimulated carrier turnover number $(P=0.05)$.

\section{The effects of phlorizin treatment}

Data in Table III show the effects of maintaining a lower hyperglycemia on the abnormalities of glucose transport system observed in the 10-d diabetic animals by phlorizin treatment. Compared with the untreated diabetics, the lower plasma glucose concentration at which these rats were exposed did not improve the basal glucose transport $V_{\max }$. Insulin stimulation significantly increased the'glucose transport $V_{\max }(P<0.001$ vs. basal $)$ but to a lower level than in controls $(P<0.001)$. Compared with the untreated diabetics, the insulin-stimulated $V_{\max }$ was increased $35 \%$ by the phlorizin treatment, although this improvement did not reach statistical significance. To test the hypothesis that the improvement in skeletal muscle glucose transport is dependent on the level of hyperglycemia, we correlated the basal, preinsulin injection, glucose concentration with the insulin-stimulated glucose transport $V_{\max }$ for each 10-d, phlorizin-treated and untreated, diabetic rat (Fig. 4). These data show that there is a significant negative correlation $\left(r^{2}=0.52, P\right.$ $<0.02$ ) between pre-insulin-injection plasma glucose concentration and insulin-stimulated $V_{\max }$, suggesting that hyperglycemia per se plays a role in decreasing the insulin-induced glucose transport $V_{\max }$. The $K_{\mathrm{m}}$ for glucose transport was similar to that of controls, both in the basal state $(24.1 \pm 2.2 \mathrm{mM}, P=0.6)$ and in the insulin-stimulated state $(43.6 \pm 5.7 \mathrm{mM}, P=0.1)$.

In Table III, $\mathbf{R}_{\mathrm{o}}$ data show that, in the basal state, phlorizin administration in the diabetic animals did not significantly increase the number of glucose transporters ( $P=$ NS vs. untreated diabetics, $P=0.02$ vs. controls). Insulin stimulation, that did

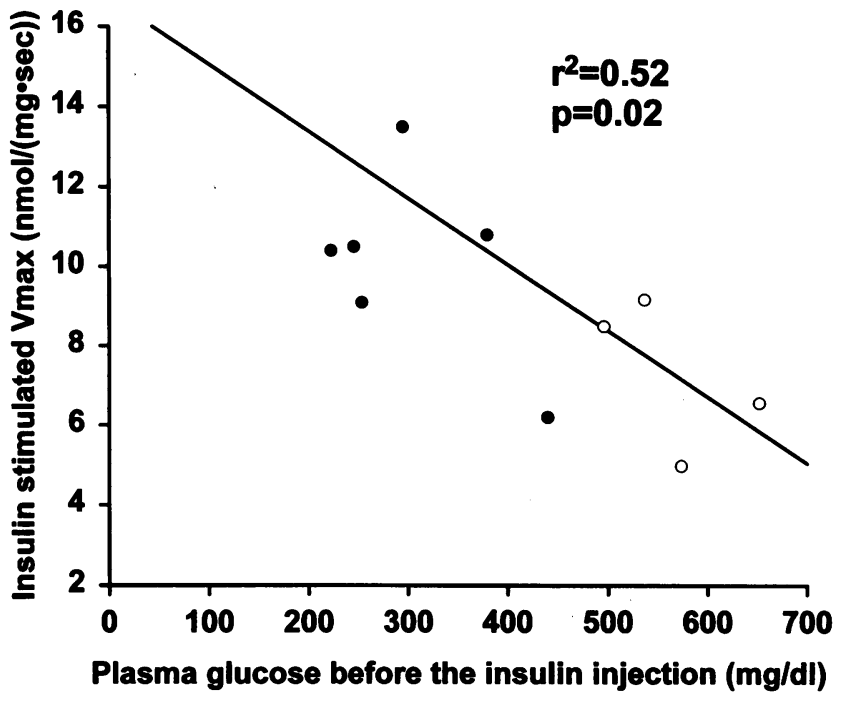

Figure 4. Correlation between the plasma glucose concentration measured in the animals before the insulin injection and the glucose transport $V_{\max }$ measured in the plasma membrane vesicles prepared from the same animals after the insulin injection (see Methods). The data represent the untreated 10-d diabetic rats $(0)$ and the phlorizin-treated 10-d diabetic animals $(\bullet)$

not induce a significant increase of $R_{0}$ in the untreated diabetics, did induce a significant translocation in the phlorizin-treated diabetic rats $(P<0.001$ vs. the basal level $)$. In addition, the $R_{\mathrm{o}}$ level reached after insulin stimulation was higher than in the untreated diabetic animals ( $P=0.01$ vs. untreated diabetics), although it was still significantly lower than in controls ( $P$ $<0.02)$. The $K_{\mathrm{d}}$ for the CB binding was similar to that of controls $(132 \pm 24$ and $135 \pm 26 \mathrm{nM}$, in the basal and in the insulin-stimulated state, respectively).

Phlorizin administration, which reduced the plasma glucose level by $250 \mathrm{mg} / \mathrm{dl}$ but did not normalize it (Table I), did not modify the GLUT4 level in the whole muscle HM in the diabetic animals (in Fig. 1). The PM GLUT4 data again parallel the $R_{o}$ data. In fact, compared with the untreated diabetics, phlorizin treatment (Fig. 2) did not change the PM GLUT4 level in the basal state $(5.03 \pm 0.4$ and $5.2 \pm 0.7$ arbitrary units, in untreated and phlorizin-treated diabetic rats, respectively). Insulin stimulation, which did not significantly increase PM GLUT4 in the untreated diabetics, did induce a significant translocation in the phlorizin-treated diabetics (from $5.2 \pm 0.7$ in the basal state to $8.4 \pm 1.5$ after insulin stimulation; $P<0.03$ ). However, the level reached was still significantly lower than in controls $(P$ $<0.001$ ). With regard to the PM GLUT1 (Fig. 3 ), there were no differences either in the basal state or after insulin stimulation, in the phlorizin-treated versus the untreated diabetic animals. Compared with untreated diabetics, phlorizin treatment did not have an effect on carrier turnover number, either in the basal state or after maximal insulin stimulation (Table III).

To summarize, the effect of phlorizin on the diabetic rats show that the reduction of hyperglycemia did not have an effect on the basal skeletal muscle glucose transport system but did partially improve the insulin-stimulated glucose transport. This improvement was associated with a significant improvement of total glucose transporter and GLUT4 translocation (Table III, Figs. 2 and 4$)$. 
Phlorizin treatment in the nondiabetic rats did not modify the $V_{\max }$, the $\mathrm{R}_{\mathrm{o}}$, or the carrier turnover number either in the basal state or after maximal insulin stimulation, compared with the controls (Table III). Both the $K_{\mathrm{m}}$ for glucose transport (36 \pm 4.0 and $40.2 \pm 5.9 \mathrm{mM}$ ) and the $K_{\mathrm{d}}$ for the CB binding $(85 \pm 6.8$ and $137 \pm 10.6 \mathrm{nM}$, in the basal state and after insulin stimulation, respectively) were also not statistically different from untreated controls. Compared with the untreated controls, the HM GLUT4 was also unchanged in the phlorizin-treated control group (Fig. 1). In the same group, compared with the untreated controls, phlorizin administration did not change the basal PM GLUT4 (8.1 \pm 1.5 arbitrary units, $P=0.1)$, whereas it reduced the insulin-stimulated PM GLUT4 level (11.4 \pm 1.5 arbitrary units, in the insulin-stimulated state, $P<0.05$, vs. untreated controls; Fig. 2), likely because of the lower 5'nucleotidase enrichment of this group (Table II). However, in this group the insulin-induced GLUT4 translocation was normal ( $P<0.04$, vs. the basal value $)$. In the phlorizin-treated controls, no differences were observed in PM GLUT1 compared with the controls, both in the basal state and after maximal insulin stimulation (from $8.02 \pm 0.7$ in the basal state to $10.2 \pm 0.9$ after maximal insulin stimulation; Fig. 3).

\section{Discussion}

Diabetes in humans is associated with impairment of skeletal muscle glucose uptake (1-5). The transport of glucose through the plasma membrane, mediated by specific carrier proteins, is the first step of skeletal muscle glucose uptake and has recently been shown to be impaired in humans with NIDDM (11). However, the exact mechanisms by which glucose transport is impaired are unknown. Theoretically there could be a decrease in transporter number, an impairment in transporter translocation and/or a decrease in transporter intrinsic activity (26). Conflicting data are available on the reduction of GLUT4 content as a mechanism of glucose transport impairment (19-25). Therefore, a major role could be played by a reduction in the transporter intrinsic activity. To clarify the mechanisms of the impaired skeletal muscle glucose transport in diabetes, we studied STZ diabetic rats at different stages of the disease. In addition we tried to clarify the role of transporter intrinsic activity, in the presence or absence of changes of glucose transporter content, on skeletal muscle glucose transport. Furthermore, to study the effects of hyperglycemia per se, we reduced the plasma glucose concentration of diabetic animals with phlorizin (40).

Our data show that the impairment of the basal state skeletal muscle glucose transport in STZ diabetes is due in part to a severe reduction of glucose transporter intrinsic activity, determined by calculation of the average carrier turnover number. In the early stages of development of STZ diabetes, when no changes in total number of glucose transporters and GLUT4 or GLUT1 content of skeletal muscle could yet be detected, the reduction of glucose transport was entirely due to the impairment of transporter intrinsic activity. On the contrary, insulinstimulated glucose transport was reduced exclusively by an impairment of glucose transporter translocation, as no significant impairment of the ability of insulin to increase carrier turnover number was detected. Finally, we found that hyperglycemia per se is associated with decreased insulin-stimulated glucose transport activity and that reduction of hyperglycemia improves insulin-induced transporter translocation.
Consistent with studies from several different laboratories (14-17, 53, 54), acute insulin stimulation in the current study did not change the whole muscle content of GLUT4 in either control or diabetic animals, indicating that net synthesis of new transporters did not occur. In addition, several authors (14-18, $53,54)$, using subcellular fractionation procedures, have clearly demonstrated that the appearance of glucose transporters in the PM after insulin stimulation is associated with a concomitant decrease in transporters in the intracellular compartment. Therefore, we consider that in the present study the insulin induced increase in glucose transporters in the PM fraction was due to the translocation of glucose transporters from an intracellular pool, although we did not directly measure the glucose transporters or the GLUT4 content in the intracellular compartment.

As shown by several studies (reviewed in references 55 and 56) on different cell types, the number of glucose transporters on the PM is regulated by the relative rates of exocytosis and endocytosis of glucose transporters from/to one or more interconnected intracellular compartments. Insulin mainly stimulates the rate of exocytosis (translocation) and only slightly reduces the rate of endocytosis. Interestingly, data obtained with the subcellular fractionation procedure (16) show that the reduced increase of the number of glucose transporters in the skeletal muscle PM in STZ diabetic rats after insulin stimulation is associated with a normal decrease of the transporter content in the intracellular pool. The possibility arises (discussed in reference 57) that, in STZ diabetic rats, the glucose transporters leave normally the intracellular pool, but migrate to a compartment other than the PM, not selected by the fractionation procedure. Alternatively, the lack of an insulin-stimulated increase of glucose transporters on the PM could theoretically be due to an increased rate of endocytosis of glucose transporters from the PM to an other intracellular compartment, which is not measured.

In the current study we show that in the control rats GLUT4 increased 50\% above the basal level after maximal insulin stimulation. Using the in vitro photolabeling of GLUT4 in the isolated soleus of 3-wk-old rats, others $(58,59)$ have shown a 78 -fold increase with maximal insulin stimulation. However, several differences are present between the fractionation procedure in the current study and the approach used in references 58 and 59, such as: in vivo vs. in vitro insulin stimulation, adult versus very young animals, soleus plus gastrocnemius vs. soleus only, and insulin concentrations used. In both references 58 and 59 , the fold increase in response to insulin was calculated in comparison to muscles incubated in the absolute absence of insulin, whereas in the current study the insulin level of our control, nonfasted rats was $50 \mu \mathrm{U} / \mathrm{ml}$ (Table I). The observations made in this study, and in references 16 and 60 , that the translocation of glucose transporters is impaired in STZ diabetes, are relative to the data from the respective control groups and the methods used. Unfortunately, there are no data available on transporter translocation in muscle of STZ diabetic animals obtained by the photolabeling approach for comparison.

The effects of diabetes on the parameters measured are summarized in Fig. 5. The progressive reduction of basal glucose transport $V_{\max }$ over time was associated with the combined reduction of PM total glucose transporter number, GLUT4 content, and carrier turnover number. The most important finding of the current study is the involvement of carrier turnover number in the reduction of basal glucose transport in diabetes. In addition, the analysis of the glucose transport system by time 

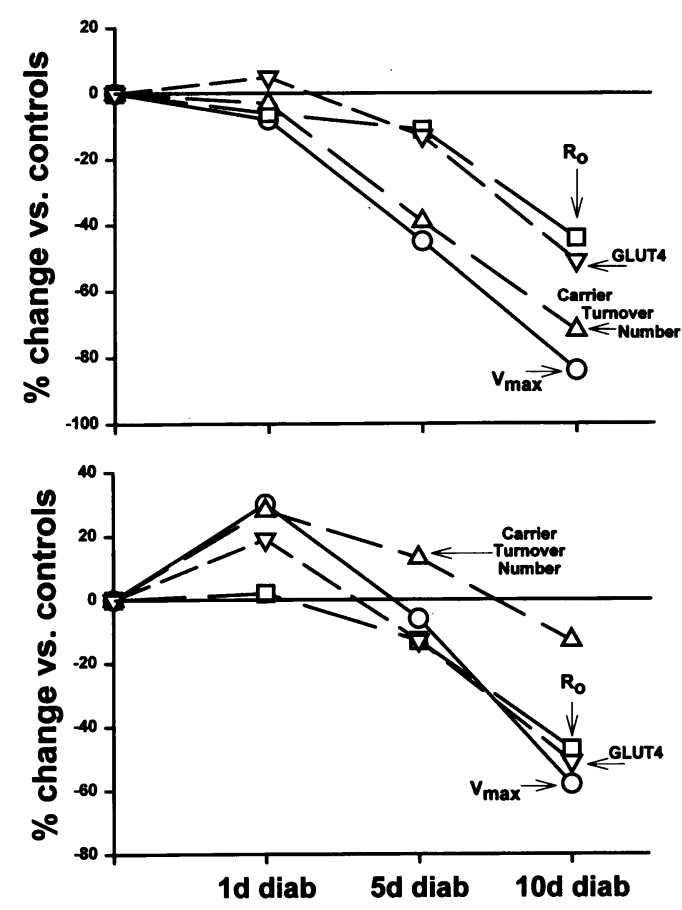

Figure 5. Percent differences for the diabetic rats versus the untreated control group of glucose transport $V_{\max }(O), \mathrm{R}_{\mathrm{o}}(\square)$, PM GLUT4 $(\nabla)$, and carrier turnover number $(\Delta)$ in the basal state (top) and in the insulin-stimulated state (bottom).

shows that by day 5 a defect of glucose transport had developed in which the impairment in carrier turnover number was the only defect that could be detected. Because the carrier turnover number is an average measurement of the transporter intrinsic activity, changes in the ratio of GLUT4 to GLUT1 on the plasma membrane that do not alter the total number of glucose transporters (measured by CB binding) could potentially affect glucose transport and modify the carrier turnover number. Under these hypothetical circumstances, although no real changes in the intrinsic activity of the single transporter isoform occur, the carrier turnover number would show a change in the average transporter activity. However, the data obtained in the 5-d diabetic animals substantially rule out this possibility (Table III, Figs. 2, 3, and 5). In these rats, not only was the total number of glucose transporters unchanged, but the plasma membrane content of GLUT1 and GLUT4 was also unchanged. Therefore, the mechanism of impaired basal glucose transport was clearly due to a reduction of the intrinsic activity of GLUT4 and/or GLUT1.

Only later in the development of STZ diabetes (10-d animals) was a reduction of PM total glucose transporter number and GLUT4 detected, confirming the work of others $(16,35$, $37,60)$. We did not find a statistically significant increase in basal PM GLUT1 content with diabetes, in agreement with data published by Klip et al. (16). In apparent contrast with this finding, other data from the same laboratory (37) have shown an increase of PM GLUT1 in 1-wk diabetic animals. However, the diabetic animals studied in reference 37 were studied under different conditions than in the current study (and in reference 16 ), because their basal insulin levels were normal compared with the control group.

Insulin stimulation in 10-d diabetic animals showed a sig-

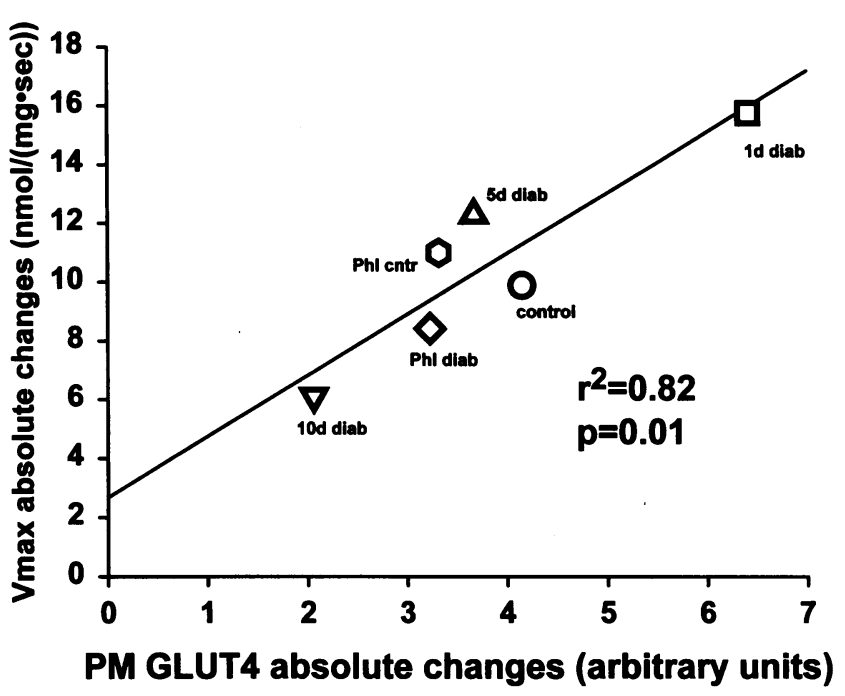

Figure 6. Correlation between absolute changes above basal after maximal insulin stimulation for glucose transport $\left(V_{\max }\right)$ and for PM GLUT4 in untreated controls $(O), 1-\mathrm{d}(\square), 5-\mathrm{d}(\Delta), 10-\mathrm{d}(\nabla)$ diabetics, phlorizin-treated 10-d diabetic animals $(\diamond)$, and phlorizin-treated controls (O). These changes are calculated as the differences, for each group, between the average values of the rats studied in the basal state and those of the animals studied in the insulin-stimulated state.

nificant increase of $V_{\max }$ compared with basal, although the absolute level reached was similar to the basal value of the controls. The carrier turnover number increased normally with insulin stimulation, and the severe reduction of the insulin-stimulated glucose transport $V_{\max }$ was primarily due to a decrease of total glucose transporter and GLUT4 translocation. Previous studies have shown a reduction in the insulin-stimulated $R_{o}(60)$ and GLUT4 (16) with STZ diabetes. Not only do we confirm these observations, we also show that the severe defect in $R_{o}$ and GLUT4 translocation is the primary mechanism responsible for the impairment of insulin-stimulated glucose transport. In the 10-d diabetic animals, the observation that the carrier turnover number increased normally in response to insulin (Table III and Fig. 5), without any significant net increase in transporter number or GLUT4 on the PM suggests that the transporters already associated with the plasma membrane become activated. Alternatively, it is possible that a net translocation cannot be demonstrated, but there is a substitution of more active transporters from an intracellular pool without a net increase in total transporter number. However, if we correlate the insulin induced changes of glucose transport $V_{\max }$ with the PM GLUT4 changes above the basal value for all the groups studied (Fig. 6 ), we obtain a positive significant correlation. This correlation confirms that the differences in the insulin-stimulated glucose transport $V_{\max }$ among the groups are mainly due to differences in translocation of GLUT4.

Our data on the 1-d diabetic animals in the basal state are in agreement with other studies showing no change of glucose transport activity (34) or whole muscle GLUT4 protein content $(34,36,61)$. However, in 1-d diabetic animals, Richardson et al. (34) found that glucose transport did not increase at all after insulin stimulation. In contrast, we found that, compared with the controls, the glucose transport $V_{\max }$ was actually greater in response to insulin stimulation, which could be explained by an increased GLUT4 translocation. In the study by Richardson 
et al. glucose transport was measured in hindlimb muscles by using the hindlimb perfusion technique and it is possible that the different findings were due to the different methodological approach. On the other hand, our observations fit very well with other data showing that in 1-d diabetic animals both insulinstimulated whole body glucose uptake $(38,39)$ and, more importantly, skeletal muscle glucose uptake (36) and transport (62) are not reduced. We can only speculate that the increased response of the glucose transport system to insulin found in the current study might be due to an effect of the period of hyperinsulinemia which occurred in the first $24 \mathrm{~h}$ after the STZ injection $(42,43)$ or an acute effect of hypoinsulinemia, and/ or, to a stimulatory effect of acute hyperglycemia per se on GLUT4 translocation (63).

Phlorizin administration in diabetic rats significantly reduced the plasma glucose concentration, although the level reached was still higher than that of the controls. Using the same amount of phlorizin as in other studies $(37,40)$ we were unable to normalize the plasma glucose concentration. In those studies, plasma glucose normalization was obtained by combining the phlorizin treatment with fasting and treating the animals for a very short period of time (37) or studying animals with a less severe initial hyperglycemia (40).

In our study, phlorizin treatment did not have an effect on the skeletal muscle glucose transport system in the basal state. Specifically, the level of PM total glucose transporters and PM GLUT4 remained unchanged. This is in contrast to a previous study (37) reporting that phlorizin treatment restored $R_{\mathrm{o}}$ and GLUT4 to normal. The reasons for the differences of the two studies could be several; first, it is possible that a complete normalization of plasma glucose is necessary to restore a normal level of PM GLUT4. However, a $250 \mathrm{mg} / \mathrm{dl}$ reduction of nonfasted plasma glucose should be expected to have some effect if hyperglycemia had an important impact. Second, we studied animals that were not fasted and were treated with phlorizin for 8-d and after 10-d of diabetes, whereas in the study by Dimitrakoudis et al. (37), they treated 5-d STZ diabetic animals with phlorizin for $2 \mathrm{~d}$ and studied them after $24 \mathrm{~h}$ of fasting.

Phlorizin administration to diabetic animals significantly improved the defect in translocation of glucose transporters in response to insulin stimulation (Table III and Fig. 2). In addition, we showed that hyperglycemia affects insulin-stimulated skeletal muscle glucose transport (Fig. 4). Therefore, because the transporter-activation process was unaffected by diabetes, we can argue that the normalization of in vivo insulin-mediated whole body glucose uptake after phlorizin treatment $(40,41)$ is due primarily to an improvement of translocation. Hence, the significant negative correlation between basal plasma glucose concentration and insulin-stimulated $V_{\max }$ (Fig. 4) suggests that the complete normalization of plasma glucose would fully correct the defect in insulin-stimulated glucose transport. Furthermore, recent data (64) obtained in muscle strips from noninsulin-dependent diabetes mellitus patients, show that the exposure in vitro of these strips to a normal glucose level normalizes their insulin-stimulated glucose transport. Thus, the finding that hyperglycemia per se affects glucose transporter translocation and glucose transport could represent an important mechanism through which hyperglycemia affects insulin-stimulated skeletal muscle glucose uptake not only in diabetic rats, but, potentially, also in human diabetes.

Phlorizin is a specific inhibitor of active glucose transport (gut and kidney), but it also has an inhibitory effect on the facilitative glucose transport in vitro $(65,66)$. However, no data were available in the literature about the effect of phlorizin on skeletal muscle glucose transport when administered in vivo. With the phlorizin-treated controls, we found that glucose transport activity, both in the basal state and after maximal insulin stimulation, was not directly affected by phlorizin administration. Compared with the untreated controls, we found a significant reduction of insulin-stimulated PM GLUT4, but this reduction was probably due to the lower purity of plasma membranes in this group ( $5^{\prime}$-nucleotidase data shown in Table II). In fact, correcting the PM GLUT4 data for the PM 5'-nucleotidase activity, no significant difference vs. untreated controls could be detected for PM GLUT4 content.

Several reports in the literature $(14,16-18)$ have shown that GLUT4 is the only glucose transporter to translocate in response to insulin stimulation in rat skeletal muscle, although a clear trend toward an increase of PM GLUT1, or decrease of microsomal GLUT1, have also been reported in the past (17, 18). However, very recently, it has been shown that in rat skeletal muscle GLUT1 translocates in response to maximal insulin stimulation, demonstrating that insulin-mediated translocation of this transporter occurs not only in adipose cells, but also in skeletal muscle (67). In addition, a strong significant reduction in GLUT1 content of the internal membrane pool after insulin stimulation in skeletal muscle tissue from mice has also been recently shown (68). In the current study, we found that the difference between basal and insulin-stimulated PM GLUT1 was highly significant $(P<0.005)$. The significance of GLUT1 translocation in skeletal muscle could be the same suggested for adipose cells $(56,69-73)$ : the translocation of GLUT1 is probably distinct from that of GLUT4 and may reflect a more general and nonspecific insulin-induced redistribution of membrane proteins from the Golgi apparatus to the plasma membrane. However, our observation that the changes induced by insulin stimulation in CB binding and GLUT4 are parallel confirms that GLUT4 is quantitatively more important. Furthermore, the fact that the changes in $V_{\max }$ positively and significantly correlate with the changes of GLUT4 in all groups confirms that GLUT4 is the major determinant of increased glucose transport after insulin stimulation (Fig. 6). In addition, we also show that STZ diabetes affects not only GLUT4 translocation, but also GLUT1 translocation in response to insulin stimulation. On the other hand, phlorizin administration, with the subsequent plasma glucose reduction, does not have any effect on the insulin-induced redistribution of GLUT1, whereas there is a significant improvement of GLUT4 translocation.

In conclusion, the reduction of skeletal muscle glucose transport $V_{\max }$ in STZ diabetes is determined by different mechanisms in the basal state vs. the insulin-stimulated state. In the basal state, a major role is played by the impairment of glucose transporter intrinsic activity that appears before any impairment of glucose transporter number. However, the severe reduction of $V_{\max }$ after $10 \mathrm{~d}$ of diabetes is due to the combined defects in glucose transporter number and activity. On the other hand, diabetes does not affect the insulin-stimulated glucose transporter intrinsic activity and the impairment of insulin-stimulated glucose transport $V_{\max }$ is due to a decrease in skeletal muscle GLUT4 content and to a severe reduction of the GLUT4 translocated to the plasma membrane. Finally, our data suggest that hyperglycemia per se affects insulin-stimulated glucose transport $V_{\max }$ by altering the glucose transporter translocation. The defect in transporter intrinsic activity, by itself or associated 
with a defect in transporter number, could represent an independent mechanism for the reduction of skeletal muscle glucose uptake in human diabetes. In addition, the negative effect of hyperglycemia on the insulin-induced glucose transporter translocation could represent a further mechanism of impairment of glucose transport in human diabetes, particularly in individuals with poor glycemic control.

\section{Acknowledgments}

We thank Dr. R. J. Smith for the gift of the GLUT4 antibody and P. M. Valyou for the assistance in the preparation of the plasma membrane vesicles.

This work was supported by U. S. Public Health Service grant RO1DK-26317 (Dr. Horton) and a grant from the Joslin Diabetes Center. Dr. Napoli was on leave from the "Federico II" University Medical School, Napoli, Italy, and supported by the American Diabetes Association Mentor-based Post-doctoral Fellowship Program (Dr. Horton) and a Mary K. Iacocca Fellowship from the Joslin Research Laboratory.

\section{References}

1. DeFronzo, R. A., R. Hendler, and D. Simonson. 1982. Insulin resistance is a prominent feature of insulin-dependent diabetes. Diabetes. 31:795-801.

2. Yki-Jarvinen, H., and V. A. Koivisto. 1984. Insulin sensitivity in newly diagnosed type I diabetics after ketoacidosis and after three months of insulin therapy. J. Endocrinol. Metab. 287:659-666.

3. DeFronzo, R. A., R. Gunnarson, O. Bjorkman, M. Olsson, and J. Warren. 1985. Effects of insulin on peripheral and splanchnic glucose metabolism in noninsulin-dependent (type II) diabetes mellitus. J. Clin. Invest. 76:149-155.

4. Capaldo, B., R. Napoli, L. Di Marino, A. Picardi, G. Riccardi, and L. Sacca. 1988. Quantification of forearm glucose and free fatty acid (FFA) disposal in normal subjects and type II diabetic patients: evidence against an essential role for FFA in the pathogenesis of insulin resistance. J. Clin. Endocrinol. \& Metab. 67:893-898.

5. Baron, A. D., M. Laakso, G. Brechtel, and S. V. Edelman. 1991. Reduced capacity and affinity of skeletal muscle for insulin-mediated glucose uptake in non-insulin-dependent diabetic subjects. Effects of insulin therapy. J. Clin. Invest. 87:1186-1194.

6. Kubo, K., and J. E. Foley. 1986. Rate limiting steps for insulin-mediated glucose uptake into perfused rat hindlimb. Am. J. Physiol. 250 (Endocrinol. Metab. 13):E100-E102.

7. Fink, R. I., P. Wallace, G. Brechtel, and J. M. Olefsky. 1992. Evidence that glucose transport is rate-limiting for in vivo glucose uptake. Metab. Clin. Exp. 41:897-902.

8. Katz, A., B. L. Nyomba, and C. Bogardus. 1988. No accumulation of glucose in human skeletal muscle during euglycemic hyper-insulinemia. Am. J. Physiol. 255 (Endocrinol. Metab. 18):E942-E945.

9. Ziel, F. H., N. Venkatesan, and M. B. Davidson. 1988. Glucose transport is rate limiting for skeletal muscle glucose metabolism in normal and STZ-induced diabetic rats. Diabetes. 37:885-890.

10. Yki-Jarvinen, H., K. Sahlin, J. M. Ren, and V. A. Koivisto. 1990. Localization of rate-limiting defect for glucose disposal in skeletal muscle of insulin resistance type I diabetic patients. Diabetes. 39:157-167.

11. Bonadonna, R., S. Del Prato, M. P. Saccomanni, E. Bonora, G. Gulli, E. Ferrannini, D. Bier, C. Cobelli, and R. A. DeFronzo. 1993. Transmembrane glucose transport in skeletal muscle of patients with non-insulin-dependent diabetes. J. Clin. Invest. 92:486-494.

12. Kahn, B. B., L. Rossetti, H. F. Lodish, and M. J. Charron. 1991. Decreased in vivo glucose uptake but normal expression of GLUT1 and GLUT4 in skeletal muscle of diabetic rats. J. Clin. Invest. 87:2197-2206.

13. Calderhead, D. M., K. Kitagawa, G. E. Lienhard, and G. W. Gould. 1990. Translocation of the brain-type glucose transporter largely accounts for insulin stimulation of glucose transport in BC3H-1 myocytes. Biochem. J. 269:597-601.

14. King, P. A., E. D. Horton, M. F. Hirshman, and E. S. Horton. 1992. Insulin resistance in obese Zucker rat (fa/fa) skeletal muscle is associated with a failure of glucose transporter translocation. J. Clin. Invest. 90:1568-1575.

15. Hirshman, M. F., L. J. Goodyear, L. J. Wardzala, E. D. Horton, and E. S. Horton. 1990. Identification of an intracellular pool of glucose transporters from basal and insulin-stimulated rat skeletal muscle. J. Biol. Chem. 265:987991.

16. Klip, A., T. Ramlal, P. J. Bilan, G. D. Cartee, E. A. Gulve, and J. O. Holloszy. 1990. Recruitment of GLUT-4 glucose transporters by insulin in diabetic rat skeletal muscle. Biochem. Biophys. Res. Commun. 172:728-736.
17. Goodyear, L. J., M. F. Hirshman, P. M. Valyou, and E. S. Horton. 1992. Glucose transporter number, function, and subcellular distribution in rat skeletal muscle after exercise training. Diabetes. 41:1091-1099.

18. Douen, A. G., T. Ramlal, S. Rastogi, P. J. Bilan, G. D. Cartee, M. Vranic, J. O. Holloszy, and A. Klip. 1990. Exercise induces recruitment of the "insulinresponsive glucose transporter." Evidence for distinct intracellular insulin- and exercise-recruitable transporter pools in skeletal muscle. J. Biol. Chem. 265:13427-13430.

19. Pedersen, O., J. F. Bak, P. H. Andersen, S. Lund, D. E. Moller, J. S. Flier, and B. B. Kahn. 1990. Evidence against altered expression of GLUT1 or GLUT4 in skeletal muscle of patients with obesity or NIDDM. Diabetes. 39:865-870.

20. Handberg, A., A. Vaag, P. Damsbo, H. Beck Nielsen, and J. Vinten. 1990. Expression of insulin regulatable glucose transporters in skeletal muscle from type 2 (non-insulin-dependent) diabetic patients. Diabetologia. 33:625-627.

21. Kahn, B. B., A. S. Rosen, J. F. Bak, P. H. Andersen, S. Lund, and O. Pedersen. 1992. Expression of GLUT1 and GLUT4 glucose transporters in skeletal muscle of humans with insulin-dependent diabetes mellitus: regulatory effects of metabolic factors. J. Clin. Endocrinol. \& Metab. 74:1101-1109.

22. Andersen, P. H., S. Lund, H. Vestergaard, S. Junker, B. B. Kahn, and O. Pedersen. 1993. Expression of the major insulin regulatable glucose transporter (GLUT4) in skeletal muscle on non insulin dependent diabetic patients and healthy subjects before and after insulin infusion. J. Clin. Endocrinol. \& Metab. 77:27-32.

23. Yki-Jarvinen, H., H. Vuorinen-Markkola, L. Koranyi, R. Bourey, K. Tordjman, M. Mueckler, A. M. Permutt, and V. Koivisto. 1992. Defect in insulin action on expression of the skeletal muscle/adipose tissue glucose transporter gene in skeletal muscle of type 1 diabetic patients. J. Clin. Endocrinol. \& Metab. 75:795-799.

24. Vogt, B., C. Muhlbacher, J. Carrascosa, B. Obermaier-Kusser, E. Seffer, J. Mushack, D. Pongratz, and H. U. Haring. 1992. Subcellular distribution of GLUT4 in the skeletal muscle of lean type 2 (non-insulin-dependent) diabetic patients in the basal state. Diabetologia. 35:456-463.

25. Lund, S., H. Vestergaard, P. H. Andersen, O. Schmitz, L. B. H. Gotzsche, and O. Pesersen. 1993. GLUT4 content in plasma membrane of muscle from patients with non-insulin-dependent diabetes mellitus. Am. J. Physiol. 265 (Endocrinol. Metab. 28):E889-E897.

26. Kahn, B. B. 1992. Facilitative glucose transporters: regulatory mechanisms and dysregulation in diabetes. J. Clin. Invest. 89:1367-1374.

27. King, P. A., M. F. Hirshman, E. D. Horton, and E. S. Horton. 1989. Glucose transport in skeletal muscle plasma membrane vesicles from control and exercise rats. Am. J. Physiol. 257 (Cell Physiol. 26):C1128-C1134.

28. Kahn, B. B., I. A. Simpson, and S. W. Cushman. 1988. Divergent mechanisms for the insulin-resistant and hyperresponsive glucose transport in adipose cells from fasted and refed rats. J. Clin. Invest. 82:691-699.

29. Kahn, B. B., and S. W. Cushman. 1987. Mechanism for markedly hyperresponsive insulin-stimulated glucose transport activity in adipose cells from insulintreated streptozotocin diabetic rats. J. Biol. Chem. 262:5118-5124.

30. Clancy, B., and M. Czech. 1990. Hexose transport stimulation and membrane redistribution of glucose transporter isoforms in response to cholera toxin, dibutyryl cyclic AMP, and insulin in 3T3-L1 adipocytes. J. Biol. Chem. 265:12434-12443.

31. Clancy, B., S. Harrison, J. Buxton, and M. Czech. 1991. Protein synthesis inhibitors activate glucose transport without increasing plasma membrane glucose transporters in 3T3-L1 adipocytes. J. Biol. Chem. 266:10122-10130.

32. Harrison, S., J. Buxton, B. Clancy, and M. Czech. 1991. Evidence that erythroid-type transporter intrinsic activity is modulated by cadmium treatment of mouse 3T3-L1 cells. J. Biol. Chem. 266:19438-19449.

33. Harrison, S., J. Buxton, and M. Czech. 1991. Suppressed intrinsic catalytic activity of GLUT1 glucose transporters in insulin sensitive 3T3-L1 adipocytes. Proc. Natl. Acad. Sci. USA. 88:7839-7843.

34. Richardson, J. M., T. W. Balon, J. L. Treadway, and J. E. Pessin. 1991. Differential regulation of glucose transporter activity and expression in red and white skeletal muscle. J. Biol. Chem. 266:12690-12694.

35. Ramlal, T., S. Rastogi, M. Vranic, and A. Klip. 1989. Decrease in glucose transporter number in skeletal muscle of mildly diabetic (STZ-treated) rats. Endocrinology. 125:890-897.

36. Youn, J. H., J. K. Kim, and T. A. Buchanan. 1994. Time courses of changes in hepatic and skeletal muscle insulin action and GLUT4 protein in skeletal muscle after STZ injection. Diabetes. 43:564-571.

37. Dimitrakoudis, D., T. Ramlal, S. Rastogi, M. Vranic, and A. Klip. 1992. Glycaemia regulates the glucose transporter number in the plasma membrane of rat skeletal muscle. Biochem. J. 284:341-348.

38. Blondel, O., and B. Portha. 1989. Early appearance of in vivo insulin resistance in adult streptozotocin-injected rats. Diabete \& Metabolisme. 15:382387.

39. Koopmans, S. J., J. A. Maassen, J. K. Radder, M. Frolich, and H. M. J. Krans. 1992. In vivo insulin responsiveness for glucose uptake and production at eu- and hyperglycemic levels in normal and diabetic rats. Biochim. Biophys. Acta. 1115:230-238.

40. Rossetti, L., D. Smith, G. I. Shulman, D. Papachristou, R. A. DeFronzo. 
1987. Correction of hyperglycemia with phlorizin normalizes tissue sensitivity to insulin in diabetic rats. J. Clin. Invest. 79:1510-1515.

41. Lisato, G., I. Cusin, A. Tiengo, S. Del Prato, and B. Jeanrenaud. 1992. The contribution of hyperglycaemia and hypoinsulinaemia to the insulin resistance of streptozotocin-diabetic rats. Diabetologia. 35:310-315.

42. Junod, A., A. E. Lambert, W. Stauffacher, and A. E. Renold. 1969. Diabetogenic action of streptozotocin. Relationship of dose to metabolic response J. Clin. Invest. 48:2129-2139.

43. Veleminsky, J., I. M. Burr, and W. Stauffacher. 1970. Comparative study of early metabolic events resulting from the administration of the two diabetogenic agents alloxan and streptozotocin. Eur. J. Clin. Invest. 1:104-108.

44. Bers, D. M. 1979. Isolation and characterization of cardiac sarcolemma. Biochim. Biophys. Acta. 555:131-146.

45. Grimditch, G., J. Barnard, S. Kaplan, and E. Sternlicht. 1985. Insulin binding and glucose transport in rat skeletal muscle sarcolemmal vesicles. Am. J. Physiol. 249 (Endocrinol. Metab. 12):E398-E408.

46. Avruch, J., and D. F. Hoelz-Sallach. 1971. Preparation and properties of plasma membrane and endoplasmic reticulum fragments from isolated rat fat cells. Biochim. Biophys. Acta. 233:334-347.

47. Bradford, M. M. 1976. A rapid and sensitive method for the quantitation of microgram quantities of protein, utilizing the principle of protein-dye binding. Anal. Biochem. 72:248-254.

48. Wilkinson, G. N. 1961. Statistical estimations in enzyme kinetics. Biochem. J. 80:324-332.

49. Wardzala, L. J., S. W. Cushman, and L. B. Salans. 1978. Mechanism of insulin action on glucose transport in the isolated rat adipose cell. J. Biol. Chem. 260:2197-2201.

50. Laemmli, V. K. 1970. Cleavage of structural proteins during the assembly of the head of bacteriophage T. Nature (Lond.). 227:680-685.

51. Towbin, H., T. Staehelin, and J. Gordon. 1974. Electrophoretic transfer of proteins from polyacrylamide gels to nitrocellulose sheets: procedure and some applications. Proc. Natl. Acad. Sci. USA. 76:4350-4354.

52. Haspel, H. C., M. G. Rosenfeld, and O. M. Rosen. 1988. Characterization of antisera to a synthetic carboxyl-terminal peptide of the glucose transporter. $J$. Biol. Chem. 263:398-403.

53. Klip, A., T. Ramlal, D. A. Young, and J. O. Holloszy. 1987. Insulininduced translocation of glucose transporters in rat hindlimb muscles. FEBS (Fed. Eur. Biochem. Soc.). Lett. 224:224-230.

54. Marette, A., J. M. Richardson, T. Ramlal, T. W. Balon, M. Vranic, J. E. Pessin, and A. Klip. 1992. Abundance, localization, and insulin-induced translocation of glucose transporters in red and white muscle. Am. J. Physiol. 263 (Cell Physiol. 32):C443-C452.

55. Holman, G. D., and S. W. Cushman. 1994. Subcellular localization and trafficking of the GLUT4 glucose transporter isoform in insulin-responsive cells. BioEssays. 16:753-759.

56. Mueckler, M. 1993. The molecular biology of glucose transport: relevance to insulin resistance and non-insulin-dependent diabetes mellitus. J. Diabetic Complications. 7:130-141.

57. Klip, A., A. Marette, D. Dimitrakoudis, T. Ramlal, A. Giacca, Z. Q. Shi, and M. Vranic. 1992. Effect of diabetes on glucoregulation. Diabetes Care. 15:1747-1766
58. Lund, S., G. D. Holman, O. Schmitz, and O. Pedersen. 1993. Glut4 content in the plasma membrane of rat skeletal muscle: comparative studies of subcellular fractionation method and the exofacial photolabelling technique using ATBBMPA. FEBS (Fed. Eur. Biochem. Soc.) Lett. 330:312-318.

9. Wilson, C. M., and S. W. Cushman. 1994. Insulin stimulation of glucose ransport activity in rat skeletal muscle: increase in cell surface GLUT4 as assessed by photolabelling. Biochem. J. 299:755-759.

60. Barnard, R. J., J. F. Youngren, D. S. Kartel, and D. A. Martin. 1989. Effects of streptozotocin-induced diabetes on glucose transport in skeletal muscle. Endocrinology. 126:1921-1926.

61. Burcelin, R., R. L. Printz, J. Kande, R. Assan, D. K. Granner, and J. Girard. 1993. Regulation of glucose transporter and hexokinase II expression in issues of diabetic rats. Am. J. Physiol. 265 (Endocrinol. Metab. 28):E392-E401.

62. Wallberg-Henriksson, H. 1986. Insulin treatment normalizes decreased glucose transport capacity in streptozotocin-diabetic rat muscle. Acta Physiol. Scand. 128:647-649.

63. Galante, P., L. Mosthaf, L. Berti, A. Okuno, H. Horikoshi, and H. Haring. 1994. Acute hyperglycemia provides an insulin independent inducer for GLUT4 translocation in rat skeletal muscle. Diabetes. 43(Suppl 1):44A. (Abstr.)

64. Zierath, J. R., D. Galuska, L. A. Nolte, A. Thorne, J. Smedegaard Kristensen, and H. Wallberg-Henriksson. 1994. Effects of glycaemia on glucose transport in isolated skeletal muscle from patients with NIDDM: in vitro reversal of muscular insulin resistance. Diabetologia. 37:270-277.

65. Kohn, P. G., and T. Clausen. 1971. The relationship between the transport of glucose and cations across cell membranes in isolated tissues. Biochim. Biophys. Acta. 225:277-290.

66. Eboue-bonis, D., and H. Clauser. 1977. The combined action of insulin and phlorizin on transport and metabolism of sugars and nucleotide turnover in the isolated rat diaphragm. Biochimie. 59:527-533.

67. Lund, S., A. Flyvbjerg, G. D. Holman, F. S. Larsen, O. Pedersen, and O. Schmitz. 1994. Comparative effects of IGF-I and insulin on the glucose transporter system in rat muscle. Am. J. Physiol. 267 (Endocrinol. Metab. 30):E461-E466.

68. Deems, R. O., R. W. Deacon, T. Ramlal, A. Volchuk, A. Klip, and D. A Young. 1994. Insulin action on whole body glucose utilization and on muscle glucose transporter translocation in mice. Biochem. Biophys. Res. Commun. 199:662-670.

69. Slot, J. W., H. J. Geuze, S. Gigengack, D. E. James, and G. E. Lienhard. 1991. Translocation of the glucose transporter GLUT4 in cardiac myocytes of the rat. Proc. Natl. Acad. Sci. USA. 88:7815-7819.

70. Slot, J. W., H. J. Geuze, S. Gigengack, G. E. Lienhard, and D. E. James. 1991. Immuno-localization of the insulin regulatable glucose transporter in brown adipose tissue of the rat. J. Cell Biol. 113:123-135.

71. Slot, J. W., R. Moxley, H. J. Geuze, and D. E. James. 1990. No evidence for expression of the insulin-regulatable glucose transporter in endothelial cells. Nature (Lond.). 346:369-371.

72. Blok, J., E. M. Gibbs, G. E. Lienhard, J. W. Slot, and H. J. Geuze. 1988 Insulin-induced translocation of glucose transporters from post-Golgi compartments to the plasma membrane of 3T3-L1 adipocytes. J. Cell Biol. 106:69-76.

73. Lienhard, G. E. 1989. Insulin may cause translocation of proteins to the cell surface by stimulating membrane trafficking from the trans Golgi reticulum. In Genes and Gene Products in the Development of Diabetes Mellitus. J. Nerup B. Mandrup-Poulse, and B. Hokfelt, editors. Elsevier, Amsterdam, 313-328. 